\title{
Evaluation of the Asymmetry of Preferences in Gifts: Characteristics, Psychological Mechanisms and Boundary Conditions
}

\author{
Liping $\mathrm{Li}^{*}$, Aimei Li \\ School of Management, Jinan University, Guangzhou, China \\ Email: ^13760847109@163.com
}

How to cite this paper: $\mathrm{Li}, \mathrm{L} . \mathrm{P} .$, \& $\mathrm{Li}, \mathrm{A}$. M. (2019). Evaluation of the Asymmetry of Preferences in Gifts: Characteristics, Psychological Mechanisms and Boundary Conditions. Psychology, 10, 539-559. https://doi.org/10.4236/psych.2019.104035

Received: February 11, 2019

Accepted: March 12, 2019

Published: March 15, 2019

Copyright (อ 2019 by author(s) and Scientific Research Publishing Inc. This work is licensed under the Creative Commons Attribution International License (CC BY 4.0).

http://creativecommons.org/licenses/by/4.0/ (c) (i) Open Access

\begin{abstract}
Gifts are the bond of interpersonal communication, but because of the role of the recipients, the asymmetry of gift evaluation is caused. This assessment of asymmetry is manifested by the huge difference between the gift chosen by the gift giver and the gift that the recipient expects, whether the gift giver knows, understands or is intimate with the recipient. Researchers believe that the factors that lead to this phenomenon are the self-centeredness of the gift giver, the over-predicted preference of the recipient, the interaction cautiousness of the two sides, the difference in the dimensions of the evaluation gifts, and so on. Some studies have also found that the process is also affected by the nature of the gift itself, environmental factors, and boundary factors such as relationship and experience. Finally, the article gives the enlightenment of commodity marketing to the two different roles of gift givers and recipients, and points out the future research direction.
\end{abstract}

\section{Keywords}

Gift Giving, Evaluation of Asymmetry, Characteristic, Psychological Mechanism, Boundary Condition

\section{Introduction}

The Gift-Giving phenomenon has a long history and is still widely concerned by Researchers. Gifts have multiple values (such as economic, social, emotional, and symbolic values) and account for a large share of consumers' daily expenses, for example, Americans spend about $\$ 130$ billion a year to prepare gifts for others (Unity Marketing, 2015). Gifts can be used to strengthen the social connection between the Giver and the Recipients (Giesler, 2006), and to establish and 
maintain social order (Ward \& Broniarczyk, 2011). Sometimes gifts involve both parties' expectations of equality (Gouldner, 1960) and sometimes the emotional expression of giftless selfless care (Belk, 1979; Belk \& Coon, 1993). However, regardless of the specific form of the gift, the gift is given to form a deep social connection between people. In real life, because of the limitations of the role, there is a huge difference between the gift chosen by the gift giver and the gift expected by the recipient. Moreover, in order to improve this social connection, gift givers tend to choose gifts that are most satisfying to the recipient or that best highlight the uniqueness of the recipient (Belk, 1996; Cheal, 1988; Otnes, Lowrey, \& Kim, 1994).

However, it is undeniable that gift giving is a major challenge in the lives of consumers. Excluding the conditional constraints encountered in the process of finding a gift, identifying the perfect gift from among many types of gifts is a test in itself. Scholar Belk (1977) believes that a key feature of a perfect gift is that both the gift and the recipient are unique and special. Extending Belk's understanding, Ruth et al. (1999) pointed out another characteristic of a perfect gift: it must be suitable for the relationship between the gift and the recipient. There are also studies that suggest that gifts need to be related to the recipient's personal preferences and tastes (Gino \& Flynn, 2011), or that gifts need to be used to remind the recipient of a particular life event and the relationship between the two parties (Belk, 1991). These are local features of the perfect gift considered from the personal point of view of the recipient. But the results are disappointing to the gift givers, because such research also finds that not all the spending on gift giving is equally beneficial, and the gifts that consumers buy are often less appreciated by the recipients than they hope (Flynn \& Adams, 2009), and in promoting the happiness of the recipients (Goodman \& Lim, 2015) and promoting the relationship between the two parties is not as effective as expected (Chan \& Mogilner, 2017).

Why can't the gift give emotional resonance between the giver and the recipient as expected by the consumer? Current research highlights the differences between gift givers and recipients in the assessment of gifts. For example, consumers have self-centered bias in gift giving, and insufficient judgment on the preferences of the recipients indicates that consumers have not or can't change empathy when making judgments or making decisions (Epley, Keysar, Van Boven, \& Gilovich, 2004; Epley, Morewedge, \& Keysar, 2004). In addition, even if the gift giver has a wide range of gift giving experience, it is still difficult for consumers to predict the level of appreciation of the recipient. Therefore, this study hopes to answer the following three questions based on the roles of the gift giver and the recipient: 1) What are the inconsistencies in the understanding of the "perfect gift" and what are the difference of asymmetry preferences in gift evaluation? 2) What is the psychological mechanism of this asymmetry? 3) Is there any other boundary influencing factor in this asymmetry? And, on this basis, this paper gives the characteristics, consequences, psychological mechanism 
and its influencing factors to evaluate the asymmetry of preference. Finally, it puts forward some marketing suggestions and future research directions.

\section{The Concept Definition and Type of Evaluation Preference Asymmetry}

\subsection{Evaluating the Concept of Preference Asymmetry}

Researchers have long noticed the asymmetry between gift givers and recipients in gift evaluation and appreciation (Adams, Flynn, \& Norton, 2012; Teigen, Olsen, \& Solås, 2005). Assessing the preference asymmetry means that due to the different roles of the gift giver and the recipient, the evaluation and appreciation of the gift are different, and even the opposite is true (Baskin, Wakslak, \& Trope, 2014). First, in the early stage of the gift selection, Flynn and Adams (2009) found that the gift giver pays more attention to the cost of the gift than the recipient, which makes it easier for the gift giver to choose the gift with the wrong standard. (such as money) to measure the value of the gift, the result is difficult to get positive feedback from the recipient; for example, the gift giver is more concerned with the gift and the recipient's preference than the recipient, so that the gift meets the recipient's peripheral preferences It looks more attractive than a gift with high emotional value (Givi \& Galak, 2017). Secondly, in the later evaluation stage of the gift, the gift giver tends to overestimate the extent to which the recipient experiences the gift emotion (Ross, Greene, \& House, 1977), and pays too much attention to his attitude towards the gift when predicting how the recipient will evaluate the gift. Or experience (Epley, Savitsky, \& Gilovich, 2002; Savitsky, Epley, \& Gilovich, 2001). These studies reveal the asymmetry of appreciation for both gifts, and in specific experiments, scholars study the asymmetry of evaluation preferences according to the different types of relationships and the different attributes of gifts.

\subsection{Assessing the Type of Preference Asymmetry}

It is very difficult to choose gifts that make the recipients like, reasonably priced, and can promote the relationship between the two parties. Therefore, the gift giver must consider the distance between the two parties and the understanding of the preferences of the recipients. Representing the depth of understanding of the recipient's preferences, but the two tend to have strong consistency) in order to make trade-offs between the different or relative attributes of the gift. First, when a consumer chooses a gift for a recipient who has an unknown preference, the trade-off is whether the gift 1) is expensive; 2) whether it is a carrier or an experience carrier; 3) More feasible or more representative of the meaning and so on. Secondly, the trade-offs that consumers need to make when choosing gifts for the generally-received recipients are: whether the gift 1) is consistent with the gift giver's characteristics or with the recipient's characteristics; 2) is to express the emotions The main is still in line with the preferences of the recipients; 3 ) is to put the symbolism in the first place or the hedonity in the first place and so 
on. Even in the case of familiarity with the recipient's core preferences, there is a need to make other trade-offs, that is, whether the gift 1) reflects the uniqueness of the recipient or the homogeneity with others, and 2) whether it is The ritual has been clearly listed; 3) highlighting the emotional value or cognitive value and so on. In short, gift givers must make trade-offs based on existing information and resources. The following highlights the three sides of the gift giver's preference for understanding, understanding and familiarity, the two sides in the evaluation of gift attributes in the evaluation of asymmetry.

1) Is it an expensive gift?

In the early gift giving, the greater the economic value of the gift, the better, is a common concern for consumers. In the past, gift givers generally believed that it is worthwhile to spend more on the recipient in order to get emotional rewards (Dunn, Aknin \& Norton, 2008; Dunn, Aknin, \& Norton, 2014). Money can represent the gift giver's careful reflection on the gift and convey to the recipient. The thoughtfulness and care of the recipients enhances the appreciation experience of the recipient. At the same time, they will feel more useful and generous, and can prove their economic independence (Segev et al., 2012).

However, the recipients expressed appreciation that the experience would not be affected by the amount of money invested (Zhang \& Epley, 2012). The amount of money does not represent the depth of emotions, nor can it replace the emotional input. Gift givers should buy truly thoughtful, considerate gifts, not more expensive gifts. As a result, expensive and inexpensive gifts are similarly appreciated (Flynn \& Adams, 2009). In addition, the monetary value of the gift perceived by the recipient is often lower than the actual cost of the gift. This shows that as a gift giver, it is difficult to fully consider the needs of the recipients, thereby increasing the economic losses caused by wrong judgments.

2) Material gifts and experiential gifts.

In addition to the price factor of the gift, the carrier of the gift is also an important attribute that affects the gift evaluation preferences. The current common classifications of carriers are: material gifts and experiential gifts. The former refers to items (ornaments or souvenirs) that can be owned by the recipient; the latter is an event that can be experienced by the recipient (concert tickets or photography lessons). Studies have shown that consumers are more inclined to provide material gifts than experiential gifts (Chan \& Mogilner, 2017). In a survey of gift givers by Chan \& Mogilner (2017), 78\% reported that the gifts they sent recently were material.

However, late feedback from the recipients found that material gifts are not as effective as experiential gifts in improving the happiness of the recipients and promoting the relationship between the two (Van Boven \& Gilovich, 2003). Specifically, experiential gifts can stimulate a variety of emotions (Bhattacharjee \& Mogilner, 2014; Chan et al., 2014; Mogilner, Kamvar, \& Aake, 2010). Compared with material gifts, the recipients can have higher satisfaction (Carter \& Gilovich, 2010) and less regrets (Rosenzweig \& Gilovich, 2012). On the other hand, it also benefits those who have a tendency to control themselves (Gilovich, Kumar, 
\& Jampol, 2015). Sharing with others (Caprariello \& Reis, 2013), strengthening self-awareness (Carter \& Gilovich, 2012), and embodying their own uniqueness (Rosenzweig \& Gilovich, 2012), the most important point is that experiential gifts do not happen with other Negative emotions brought about by comparisons (Carter \& Gilovich, 2010). This shows that there is a difference in the feelings of both parties, and the gift giver ignores the experiential gift choice that can greatly enhance the happiness of the recipient.

3) Feasible gifts and desirable gifts.

In addition to the above two points, the gift giver needs to choose between the gift and the ideal or reality. Among them, a desirable gift refers to a gift that is very attractive, and a viable gift refers to a gift that is very convenient or easy to use. The comparison of these two gifts comes from the difference in the study of consumers making decisions for themselves and for others. When making decisions, people tend to think more about others (choose a more preferred vacation plan) and pay more attention to their own viability (choose a more preferred vacation plan) (Lu, Xie, \& Xu, 2013; Xu \& Xie, 2011). Similarly, in gift giving, the gift giver has a more psychological preference for the gift (none is not a direct user of the gift), resulting in a more preferred gift (Baskin \& Wakslak, 2017).

However, this trade-off does not meet the preferences of the recipient. For example, a gift giver needs to choose between two Italian restaurant vouchers with the same denomination. One of the restaurants may have a slightly better food but a farther distance. The other restaurant has a good food but a closer distance. The lover prefers the latter to the gifter (Baskin \& Wakslak, 2017). Because the gift has a strong function-perceived utility-is an additional criterion for the recipient to assess the value of the gift (Larsen \& Watson, 2010), which is also a key indicator of feasibility. Feasible gifts can not only stimulate the positive emotions of the recipients, but also have higher satisfaction. This shows that the difference in perspective between the two can easily lead the gift giver to choose the "invisible" gift, and even cause the recipient to experience the idle and negative reception of the received gift.

The above summarizes the trade-offs faced by gift givers in choosing gifts for those who prefer to be unknown. It can be found that the price factor, the carrier of the gift and the attributes of the gift may trigger the asymmetry of the evaluation of the two parties' preferences, which leads to the adverse consequences of the gift. But this kind of risk is not only happening at an early stage. In the case of a preliminary understanding or even familiarity with the recipient, the case of giving a gift is still happening.

4) Gifts with high emotional value and matching gifts with peripheral preferences.

In the absence of a deep understanding of the recipients, the relationship between the two parties is likely to be in the stage of initial establishment and needs to be further deepened. At this point, the gift giver often grasps the peripheral preferences of the recipient (for example: preferred photos or stores, etc., different from core preferences, such as: favorite idols or most desirable cities, 
etc.), and will also show High-intensity motivation for emotions. But studies have shown that gifts with high emotional value often do not meet the personal preferences of the recipient, and the two are often negatively correlated (Yang \& Galak, 2015). Therefore, the gift giver still needs to choose between a gift of high emotional value and a gift that matches the peripheral preferences of the recipient. Among them, gifts of high emotional value (such as handicrafts or souvenirs) can be used to remind special events and important others in life (Belk, 1991), and also provide long-term happiness for the recipients. Further research has shown that gift givers prefer to present the former (Givi \& Galak, 2017) than the recipients in the face of gifts and high-value gifts that meet the recipient's peripheral preferences.

The reason is that the gift giver believes that as long as the gift that meets the preferences of the recipient is sure to be liked, it is not sure how much the other person likes. In contrast, the recipient's attitude toward a gift of high emotional value is good or bad, and the gift giver is completely uncertain. This strong fear of uncertainty led to the abandonment of gifts of high emotional value. Conversely, the recipients believe that gifts of high emotional value are more attractive than gifts that only fit their own peripheral preferences, and that such gifts are more effective in terms of enhancing relationships or improving happiness (Givi \& Galak, 2017). This shows that consistent with the preferences of the recipients, sometimes gives us the wrong selection criteria and brings a negative experience to the interaction between the two parties.

5) A gift that is consistent with the gift giver and a gift that is consistent with the recipient.

Without a deep understanding of the recipients, there is still a need to further strengthen trust and promote goodwill between the two parties. The gift giver also needs to consider giving a gift that is more consistent with oneself or a gift that is more consistent with the recipient. While it is important for gift givers to recognize the social relationship with the recipient, it is important to recognize the importance of the recipient's preferences and aspirations (Flynn \& Adams, 2009). Therefore, giving gifts that reflect the characteristics of the recipient should be the most beneficial, but this is not easy at the beginning of the interaction, and the gift giver is not good at making predictions of preferences, so that there is a prediction bias, and if the prediction is wrong, some Gifts that strongly disregard the identity of the recipient or preferences can weaken the social bond between them and undermine the quality of the relationship between the two parties (Ruth et al., 1999).

Conversely, giving a gift-centered gift is not only relatively easy, but is more likely to give the recipient a good impression. Studies have shown that giving gifts that reflect the true self of the gift giver is actually beneficial to the relationship between the giver and the recipient (Aknin \& Human, 2015), which can make the recipient more happier and more appreciated (Tamir \& Mitchell, 2012; Paolacci et al., 2015), it is also possible to rebuild and protect the identity of the gift giver (Klein et al., 2015; Segev et al., 2012). The reason is that such a gift not 
only reflects the value of the gift giver's self-exposed behavior, but also reflects the identity of the gift giver, thus enhancing interpersonal trust and goodwill. This suggests that a gift that is consistent with the characteristics of the giver may be a social resource that the consumer has not fully utilized.

6) New charity gifts and traditional general gifts.

In the absence of a deep understanding of the recipient, the gift giver will also carefully consider the symbolic value of the gift. Because the symbolic nature of the gift embodies the impression of the identity or quality of the giver in the recipient's consciousness. A symbolic gift, such as a charitable donation, will help reflect the good identity of the giver, compared to the pleasant personal experience that the traditional general gift brings to the recipient. Moreover, when selecting such a gift, the gift giver expects to help the third party in the name of the recipient, giving the recipient a sense of satisfaction and happiness after the act of altruism. This intangible gift, with a transparent spending record, is becoming more popular in Western countries (Maciejewsky, 2008).

However, studies have shown that gift givers are more concerned with the symbolic meaning of charitable donations than recipients, and are more willing to believe the indirect psychological benefits of such gifts to the recipients, misrepresenting the recipients' gifts for charitable donations. Appreciation. And the nature of their mispredictions is closely related to the nature of the relationship between the two parties. The less familiar the long-distance recipients, the more serious the biases of the gift givers (Cavanaugh, Gino, \& Fitzsimons, 2015), but for intimate people. Gift givers will be more willing to choose traditional gifts, because such gifts will make the recipients happier (Dunn, Aknin, \& Norton, 2014). However, whether they are long-distance or close-up recipients, they are more concerned with the gift's enjoyment experience and the type of gift exchange, and less concerned with what the gift wants to express. Moreover, the recipients tend to think that charitable donations are more representative of the giver than the gift giver's commitment to the relationship, resulting in a loss of perceived commitment (Dunn, Aknin, \& Norton, 2014).

From the above discussion, it is found that gift givers are more prone to prediction bias when they do not know or generally understand the recipient. In order to avoid the above common traps of gift giving because of the ignorance of the recipient's preferences, some researchers want to explore whether the preferences of the recipients can be clearly informed to prevent the above deviation behavior, but the results show that the gift givers still face Give a mistake, but the type is slightly different.

7) Requested gifts and unsolicited gifts.

In the case of a deep understanding of the recipient, the gift giver needs to continue to strengthen the benign relationship between the two parties. This also means that the gift giver still needs to give gifts to the recipients on special occasions such as weddings. A series of studies have found that even if the recipient clearly indicates his or her needs and preferences by means of a gift list or a website publicity, the above assessment of asymmetry may not be eliminated (Gino 
\& Flynn, 2011; Ward \& Broniarczyk, 2011). Although the gift givers' intentions are good, they lack the social significance of how the recipients interpret the gifts. Specifically, in a gift, the gift giver may not pay close attention to the list of gifts directly listed by the recipient. Gift givers believe that gifts that are not on the list are more considerate and more powerful signals of relationship value (Gino \& Flynn, 2011). Unexpected gifts are more likely to trigger more intense surprises, which in turn lead to greater happiness and appreciation (Ward \& Broniarczyk, 2011). So they will try to identify a gift that seems to be appropriate and buy an unclaimed gift. It seems that such a gift can express the sincere attention to the recipient and make the gift more personalized and meticulous.

Contrary to this, the recipients are more willing to accept the cash or gifts they explicitly request (Gino \& Flynn, 2011; Ward \& Broniarczyk, 2016); if the giver prepares the gift exactly as the giftor asks, instead of trying to "Thoughtful and thoughtful" is the origin of the gifts they don't explicitly ask for (Gino \& Flynn, 2011), and the recipients will be happier; other studies also show that what really makes the recipient happy is the explicit request rather than the gift list. Gifts inside (Bradford \& Sherry Jr., 2013; Ward \& Broniarczyk, 2011). Because the recipient prefers to choose a gift from a set of expected items compared to a non-designated alternative to the gift, the recipient will be frustrated when the giver does not pay attention to the clear advice he has given.

8) A unique gift and a gift of the same preference.

In addition, the gift giver needs to decide how to prepare a suitable gift for different recipients at an adjacent time. Studies have shown that gift givers tend to focus too much on what they already know when choosing gifts for the recipient, trying to convey their thoughtfulness to the recipient (Steffel \& Le Boeuf, 2013) and showing self-centered prejudice (Epley et al., 2004). In addition, research shows that when a gift giver chooses gifts for multiple recipients at the same time, it may not consider each gift the favorite gift, but sort the recipient's preferences and finally determine a certain A favorite gift of a recipient relative to others (Zhang \& Epley, 2012). The giver tries to prove that he has been thoughtful and understands the uniqueness of each recipient and gives each recipient a different gift, which is likely to lead to "over-consumption".

At the same time, because the gift giver chooses an over-personalized gift rather than a gift based on the recipient's core preferences, the recipient often does not like such a gift (Zhang \& Epley, 2012), and Such a gift is very disappointing. However, this kind of erroneous situation can be alleviated by the alienation relationship. For example, in order to reduce the probability of making mistakes and to make the recipients appreciate, the alienated friends are more willing to give gifts that are definitely popular than the close friends. Choosing a gift that is more certain and consistent with the recipient's preferences may result in a more satisfying recipient (Zhang \& Epley, 2012).

9) Gifts of short-term emotional value and gifts of long-term rational value.

In the case of a deep understanding of the recipient, facing a special holiday (such as Valentine's Day or Christmas), the two sides still face a compromise 
between the emotional and cognitive attributes of the product. This is because emotions and cognition tend to process information in different ways and produce different assessments. The emotional attributes cause direct and transient emotional responses, while cognitive attributes tend to produce long-term and stable cognitive assessments. Studies have shown that positive emotions (e.g, love, pride, gratitude, etc.) have a positive impact on gift giving, encourage gift exchange (de Hooge, 2014), and hope that the other side will report positive emotional feedback. The gift giver will pay more attention to the direct emotional response of the recipient, for example, to see the other person's happy smile. Therefore, gift givers like to present a beautifully wrapped gift (Sherry Jr., 1983), giving a gift (Yang \& Urminsky, 2015) that agrees (a bunch of blooming roses or a gift card that can be redeemed immediately), and expects both to take Come to higher emotional feedback.

In contrast, the value-seekers prefer to have a balance between emotion and reason (a bouquet of roses that can be enjoyed for a longer period of time, or a delayed gift card with a higher value). There by achieving higher overall benefits and long-term satisfaction (Yang \& Urminsky, 2015). And, it should not be overlooked that because of the pressure brought by social norms-not expressing appreciation for gifts will be seen as lack of gratitude, and may even directly damage the relationship between the two parties (Roster, 2010), leading to the real emotions of the recipients, It is likely to be hidden. Even the recipient may distort or convey the opposite inner feeling (Sherry Jr., 1983). This suggests that relying on the smile signal given by the other party to select a gift with high emotional value may lead to the failure of gift selection.

It can be seen from the above studies that at any stage of the development of the relationship between the two parties, there may be inconsistencies in the evaluation preferences, which is a self-centered selection perspective of the gift giver without knowing the preferences of the recipient; understanding the peripheral preferences of the recipient At the time, over-predicting the preferences of the recipients or interacting with caution, and when the preferences of the recipients are known, the differences in the dimensions of the gifts evaluated by the two parties are closely related. Below, this article will focus on the psychological mechanisms that assess the bias of preferences at different stages.

\section{The Psychological Mechanism of Impact Assessment Asymmetry}

\subsection{Self-Centered Tendency}

Gift givers and recipients assess the asymmetry of preferences may be because consumers tend to be self-centered when making choices for others, but they often don't realize that their views differ from the recipients. Just as gift givers emphasize the value of time and money invested in choosing gifts, perceived costs are obvious to them, but there is no difference to the recipient (Flynn \& Adams, 2009; Zhang \& Epley, 2012). When evaluating potential gifts, the gift giver may emphasize the different characteristics (uniqueness) of the gift or se- 
lection process than the recipient (Flynn \& Adams, 2009; Gino \& Flynn, 2011; Steffel \& Le Boeuf, 2013). At the same time, consumers tend to over-emphasize their own opinions when predicting how others evaluate their behavior (Epley, Savitsky, \& Gilovich, 2002; Savitsky, Epley, \& Gilovich, 2001) and overestimate the recipients' shared views. The degree (Nickerson, 1999; Van Boven, Dunning, \& Loewenstein, 2000) and the degree of understanding of themselves (Gilovich, Savitsky, \& Medvec, 1998; Gilovich, Medvec, \& Savitsky, 2000). And, if the giver believes that his thought process will be reflected in the recipient's evaluation (Zhang \& Epley, 2012), they are more likely to pay attention to the symbolic meaning of the gift, and more likely to leave their own when choosing a gift. Ideas and imprints.

\subsection{Interpersonal Interaction Caution}

The nature of the asymmetry of the assessment preferences of the gift giver and the recipient may also be related to the cautious interaction between the two the dislike of the debt experience and the fear of uncertainty about the preferences. First of all, too much pursuit of economic value will lead to an imbalance in the relationship between the two sides. In the gift, not any kind of value can produce satisfaction. For example, in business situations, perceiving personal value reduces the recipient's return intentions, and in personal situations, over-utilitarian opportunities reduce the recipient's return intentions (Antón, Camarero, \& Gil, 2014). Second, Givi \& Galak (2017) point out that when choosing between a gift of surface attributes and a gift of emotional value that matches the preferences of the recipient, the gift giver prefers to choose the former, and the recipient More willing to accept the latter. This asymmetry seems to be because the gift giver is more affirmed by the recipient's preference for the gift that matches the recipient's preference, and whether the emotionally rich gift is more skeptical for the recipient's heart. Finally, in the gift selection that is consistent with the characteristics of the gift, the gift giver is worried that the gift with the core of the gift does not match the taste of the recipient and gives up the choice, but the recipient feels that the gift with the gifter is in the early stage of the interaction. Helps to enhance interpersonal trust and affection (Aknin \& Human, 2015). Therefore, the interpretation and maintenance of the relationship between the gift and the recipient are easily affected by the cautious attitude.

\subsection{Over-Predicting Other People's Preferences}

Conversely, focusing on the other side rather than on the self may also be an important factor in assessing the asymmetry of preferences. Because the recipient-centered tendency may actually increase rather than reduce the self-other differences in the decision-making process, leading to the donor's misinterpretation of the recipient's wishes and making predictions about the recipient's preferences and reactions. Errors (Flynn \& Lake, 2008; Kenny \& Acitelli, 2001; Lerouge \& Warlop, 2006). For example, gifts often choose luxury or expensive 
products, erroneously linking economic value to the appreciation of the recipient (Flynn \& Adams, 2009). This over-concern with the experience of predicting the reaction of others or trying to read the idea of the recipient (Epley, Morewedge, \& Keysar, 2004) may lead the giver to form an abstract psychological representation of the recipient (Baskin et al., 2014). In turn, the individual preferences of the recipients are overestimated (Lerouge \& Warlop, 2006), and prediction failures occur (Epley, Keysar, Van Boven, \& Gilovich, 2004; Epley, Morewedge, \& Keysar, 2004). For example, in order to highlight the special features of each of the recipients, prepare an over-personalized gift-select the "appropriate gift" that you think can distinguish the recipient from others clearly, highlighting one's own Be considerate; or choose a gift that is not requested by the recipient to indicate the meticulousness and thoughtfulness of the selection.

\subsection{Value Assessment Bias}

The asymmetry of the gift giver and the recipient to assess the preference may also result from the way the gift giver and the recipient receive a measure of the value of the gift. The recipient is the real consumer of the gift. When evaluating the value of the gift, the psychological distance from the gift is closer, and the psychological distance from the gift giver is farther; the gift giver is the purchaser of the gift, and the psychological distance from the gift is far from the evaluation of the gift. And the psychological distance from the recipient is closer. Therefore, the mismatch of this psychological distance determines the value of the gift. For example, if you buy a gift that is too expensive, it will have a rebate burden on the recipient of the general relationship. If you buy a gift with a lower price, the recipient may also react adversely. Moreover, the recipients have misinterpreted the gifts that are too personal. Similarly, juxtaposing multiple recipients may highlight the differentiating characteristics of each of the recipients' preferences, making certain gifts temporarily appear more appropriate than their isolated looks, thereby distorting their perception of the best gift. Gifts, whether expensive, cheap, or personalized, should be considerate and focused on the individual needs, trait preferences, and personal values of the recipient, and match the core characteristics of the recipient or giver, rather than the price of the gift.

As can be seen from the above discussion, during the gift giving, the gift giver lacks the preference information of the recipient (Belk, 1977), the misplacement of the relationship between the two parties (Caplow, 1982), the neglect of the preference (Gino \& Flynn, 2011) and the differential interpretation of gifts (Baskin et al., 2014) may lead to asymmetry in the assessment of preferences in the above gifts. The current research is mainly divided into two aspects of personal and interpersonal influence to explore this asymmetry. The first branch tests the recipient's response to the gift, focusing on identifying which gifts would make the recipient more like and appreciated (Flynn \& Adams, 2009; Gino \& Flynn, 2011; Zhang \& Epley, 2012), the second The branch focuses on finding out which gifts can promote the relationship between the giver and the recipient (Aknin \& Human, 2015). For example, let the perceived closeness (Kok 
\& Fredrickson, 2010; Kok et al., 2013) establish the tightness of the connection (Hutcherson, Seppala, \& Gross, 2008; Dibble, Levine, \& Park, 2012). These results promote or hinder the development of relationships and are also affected by the following boundary conditions.

\section{The Boundary Conditions Affecting the Evaluation of Asymmetry}

\subsection{The Role Will Affect the Asymmetry of Evaluation Preferences}

1) The perceived cost of both parties' preferences. The cost of the gift giver consists of three parts: currency, effort and time (Wooten, 2000). Among them, the relationship between monetary value and the emotional expression of gifts is not close. The sacrifice of effort and time illustrates the importance that the gift giver pays to the recipient. Therefore, on the one hand, valuable gifts are more likely to be perceived as expensive. On the other hand, the recipients prefer gifts that require a lot of time and effort from the gift giver, and when the cost of the gift is high, the economic value is Secondary (Gino \& Flynn, 2011). This aspect of sacrifice shows that the recipient recognizes the "psychological investment" of the gift giver (Areni, Kiecker, \& Palan, 1998), such as hand-made gifts or gift-giving gifts.

2) Gift giver's gift experience. The gift giver will spontaneously classify the recipient as "easy" or "difficult" based on past experience. Among them, "easy" type of recipients are often children or close friends, while "difficult" type of recipients are often older or more distant relatives or friends (Otnes et al., 1994). In addition, wealthy recipients-those who seem to have everything-are considered to be unsatisfiable, making buying gifts a highly anxious and time-consuming act (Wooten, 2000). The gift giver must adjust the gift selection strategy according to the category of the recipient and the feedback from the previous gift, so that the recipient feels affirmation of self (Belk \& Coon, 1993). In addition, the gift experience provides a reference for the behavior of the gift giver. For example, in romantic relationships such as marriage, expressing love is only a function of gifts. In the later stages, gift giving may be an excellent choice for forgiveness and avoidance of quarrels (Schiffman \& Cohn, 2009).

3) The clarity of the recipient's preferences. Gift givers may be more inclined to consider the clearer's clear advice in the case of being less familiar with the recipient. In this case, the gift giver does not have confidence in the recipient's knowledge enough to consider another option that is not on the gift list. Also, when the recipient asks for a particular gift, the difference in assessing the asymmetry of the preference is reduced (i.e., the gift giver is more likely to purchase the designated gift and receive the true feeling of the recipient). When the recipient's preferences are unclear, if the gift giver can choose a gift that accurately reflects the recipient, the recipient-centered gift can promote positive relationship outcomes (Neff \& Karney, 2005; Luo \& Snider, 2010). However, once the prediction is wrong, certain gifts that do not conform to the identity of the 
recipient or preferences may compromise the quality of the relationship between the parties, weaken the social bonds between them, and even undermine the relationship (Ruth et al., 1999).

\subsection{The Nature of the Gift Will Affect the Asymmetry of the Evaluation Preferences}

The nature of the gift is the main determinant of the level of interpretation. For example, consider buying a vacation for the distant future. In this case, both the gift giver and the recipient can use the same abstraction to think about the distant future, so both may pay more attention to the desirability and eliminate the asymmetric preferences we find in the research. Specifically, Gilbert and Wilson (2000) describe asymmetry as a lack of coordination between what is desired and what is actually happy. This misunderstanding may include things that don't actually make us feel happy as predicted, or things we want to avoid don't actually make us feel bad as predicted. For example, due to the abstract mindset, gift givers may underestimate the ability to use self-control when using potential gifts (Fujita et al., 2006). An emotionally-based gift may actually benefit the recipient more, especially if the recipient is often over-controlled and does not want to enjoy a material gift of pleasure (Keinan \& Kivetz, 2006).

\subsection{Interpersonal Relationship Will Affect the Asymmetry of Evaluation Preferences}

The intimacy of relationships may influence gift selection (Ward \& Broniarczyk, 2011). Researchers have suggested that when choosing gifts for intimate recipients, the gift givers have greater ability and motivation to use the recipient's perspective because of their familiar preferences, and the gift giver will be more I like to choose traditional emotional gifts, because such gifts will make the recipients happier (Dunn, Aknin, \& Norton, 2014), and will also strengthen the psychological connection between the two sides (Pickett, Gardner, \& Knowles, 2004). However, for people who are far away, the gift giver lacks a close social and psychological connection, is not sure about the preferences of such recipients, and is more likely to have their own ideas when choosing gifts. If the giver believes that his thought process is reflected in the gift giver's evaluation (Zhang \& Epley, 2012), they are likely to pay attention to the symbolic meaning of the gift. Moreover, if there is a good impression and a thoughtful motivation, the presenter may be more inclined to choose socially responsible gifts, but also pay more attention to the value of such gifts. In addition, there are different gift selections at different stages of the relationship. In the unfamiliar stage, gift-centered gifts are more feasible, increasing self-exposure and identity expression and allowing the recipient to have a psychologically secure sense of borders and increased trust; When the gift is consistent with the other party, the recipient can appreciate the attention and intention of the gift giver, and there is a sense of satisfaction that is understood, and it can enhance each other's goodwill. 


\subsection{Environmental Differences Will Affect the Asymmetry of Evaluation Preferences}

1) Occasion type. There are many occasions where you can give a gift. However, the types of values expressed on different occasions are different. For example, a gift season such as Christmas or Valentine's Day is a typical commercial occasion (Rugimbana et al., 2003), and everyone expects to receive and give back gifts (Gino \& Flynn, 2011). At this time, the two parties used a uniform exchange rule under this traditional exchange ceremony (Schiffman \& Cohn, 2009), and the recipients paid back when they perceived the economic value of the gift, while assessing or quantifying the relationship between the two parties. In addition to commercial occasions, there are more personal events, such as birthdays, anniversaries and other types of personal anniversaries. In this case, the symbol and expression value of the gift have a greater significance for maintaining the relationship between the two parties. If the recipient receives a very personal gift in a commercial setting, it will make the recipient feel uncomfortable about what kind of gift they should give back, and will also reduce the intention of return (Schiffman \& Cohn, 2009). Another example is that money, from grandparents to grandchildren's appropriate gift-money, may be problematic for romantic occasions; humorous gifts for bachelor parties may not be appropriate for Valentine's Day.

2) Cultural factors. The ability of gifts to coordinate and enhance interpersonal relationships is common in different cultures, as evidenced by the study of collectivist cultures, such as Asians (Wong et al., 2012) and South American countries. But there are also literatures that analyze the differences in gift giving behavior between Western and Asian cultures (Joy, 2001). The purpose of gifts is different in different cultures. In Asian culture, gift giving involves the exchange of gifts designed to establish relationships and establish a norm of reciprocity, which is "reciprocity". Reciprocity in the family environment is discouraged. In contrast, the situation of family and intimacy in Western culture will be more reciprocal. Gifts are a way of expressing love, gratitude and friendship to family and friends. It is worth mentioning that Asians are more inclined than North Americans to attribute gifts to self-motivation (Shen, Wan, \& Wyer, 2011). It may be counterproductive to give a gift-centered gift repeatedly because it may indicate Self-indulgence or narcissism. Gifts that match the characteristics of the giver may exacerbate these attributions and ultimately result in a lower value for the gift. Different cultures have different understandings of this. Values in the West emphasize individualism, while values in the East emphasize consistency, so gift givers may be more inclined to personalize gifts in the West than in Eastern culture (Bond \& Smith, 1996).

\section{Practice Enlightenment}

1) When buying gifts, reduce your reliance on price factors. The recipients do 
not pay special attention to the price of the gift when they evaluate the gift. The price is not the premise or label of the gift value, so the gift giver should reduce the dependence on the price when purchasing the gift, and buy the gift with higher price. Will not give more appreciation to the recipients (Flynn \& Adams, 2009). The amount of money does not represent the depth of emotions, nor can it replace the input of emotions. Therefore, gift givers should buy truly thoughtful and considerate gifts instead of more expensive gifts.

2) In the early stages, consider a gift that is consistent with the core characteristics of the giver; in the later stages, consider a gift that is consistent with the core characteristics of the recipient. Because in the early stages of the interaction, it is more feasible to give gifts based on the gift giver. This kind of self-exposure not only increases the understanding of the other party through the consistency of identity expression, but also gives the recipient a psychological security boundary and strengthens trust. After learning the recipient's preferences later, if you still only send yourself a gift, you feel that you are narcissistic, but when you give the same gift, you can let the other person know and pay attention to him. Accurate, there will be a sense of satisfaction that is understood, and it will enhance each other's goodwill.

3) Choosing a gift is a trade-off between the gift giver and the recipient. We recommend that, in the general understanding of the recipient, do not use the self- or recipient-centered point of view, and the gift giver knows that the recipient will also use the gift when choosing a gift. Their psychological distance from gifts will be relatively high. At the same time, because gift options often differ in two important ways, it helps gift givers to more quickly distinguish the value of gifts with different attributes, so that choices are more feasible, more considerate, more emotional, more needed, and more A gift that is consistent with the recipient. On the other hand, when the psychological distance between the giver and the recipient is small enough, the level of interpretation of the giver is similar to the level of interpretation of the recipient. This also helps the gift giver to first consider their preferences before choosing a gift, helping them to better meet the recipient's choice by lowering the level of interpretation. Also, asking the gift giver to recall their acceptance of a gift that was explicitly requested may help them recognize the benefits of complying with the direct request of the recipient.

4) Note the boundary conditions. When the ritual is most likely to give up the more popular gift, and suggest interventions to help the giver choose a gift that may be better. According to the past gift experience, the known degree of the recipient's preference, and the cultural environment in which the two parties are located, the gift giver may be reminded of the gift misunderstanding.

In short, we hope that the current work will provide insight into the ideas of the giver and the recipient and provide some ideas for the researchers. But most importantly, we hope that the current research will guide the gift givers to make gift decisions and make them happier in giving gifts. 


\section{The Future Research Direction}

First, future research can explore the mediating mechanisms that influence the relationship between the emotions induced by experiential gifts. Research has shown that gift givers who share experience gifts with the recipient can also strengthen interpersonal relationships. The middle reason is whether the recipient associates consumer sentiment with the relationship between the two: whether sharing a shared experience can increase the sense of intimacy; or through an indirect process: think that the gift giver enriches their life? In addition, although experience gifts are more likely to improve the quality of the relationship than material gifts, but because the gift giver may not be interested in the interest of the recipient, it is easy to underestimate the advantages of the experience gift, so the gift giver will choose to give intimacy The recipient's experience gift, while giving the material gift of the alienated recipient, gives the part of the recipient a negative gift experience. Future research can explore whether there are boundary conditions to improve this situation.

Second, future research can investigate how gift givers should balance the match with the characteristics of the gift or the recipient. The existing literature reveals the boundary between cultural factors and the relationship with the recipient, whether the preferences of the products we record consistent with the identity of the recipient are summarized in addition to the gifts, and whether the cultural differences meet these results. Subsequent research may further determine which of the dimensions that the recipient desires to be able to present to reflect the characteristics of the gift giver, and whether such expectations match the actual choice of the giver is critical.

Furthermore, future research can explore whether the gift giver's gift experience has a regulatory effect on the asymmetry in gift evaluation preferences. An important variable that has not been considered in most studies is whether the donor has direct experience with the subject being given. In most studies, many gifts are given to the gift giver to choose among items that have not been used before.

At the same time, you can explore other motivations for gifts from gift givers. For example, the motivation to support a gift giver to make a recipient happy can be understood as a desire to trigger a positive emotional response, such as a smile of the recipient. These studies have taken a different approach, opening up the appreciation of the recipients for the gift, emphasizing the gifter's pursuit of the spontaneous response of the recipient's emotional response (i.e. facial expressions, vocal expressions or gestures) and have fun. Therefore, givers often choose gifts to maximize the emotional display of the recipient and give up the choice of gifts that the recipients appreciate. That is, it is consistent with the motivation of the gift seeker to "seek a smile".

Finally, future work can explore other psychological mechanisms in which gifts evaluate inconsistencies, which may play a role in the asymmetry documented in current work, and examine how the psychological mechanisms of 
current work may play a role in other gift asymmetries. For example, with regard to the former, emotionally valuable gifts may be interpreted by the gift giver and the recipient as quite thoughtful, but the different weights of both parties (Zhang \& Epley, 2012) may lead to mismatches. Regarding the latter, consider the trade-off between immediate but smaller gifts and delayed but overall superior gifts (Yang \& Urminsky, 2015).

\section{Conflicts of Interest}

The authors declare no conflicts of interest regarding the publication of this paper.

\section{References}

Adams, G. S., Flynn, F. J., \& Norton, M. I. (2012). The Gifts We Keep on Giving: Documenting and Destigmatizing the Regifting Taboo. Psychological Science, 23, 1145-1150. https://doi.org/10.1177/0956797612439718

Aknin, L. B., \& Human, L. J. (2015). Give a Piece of You: Gifts That Reflect Givers Promote Closeness. Journal of Experimental Social Psychology, 60, 8-16. https://doi.org/10.1016/j.jesp.2015.04.006

Areni, C. S., Kiecker, P., \& Palan, K. M. (1998). Is It Better to Give than to Receive? Exploring Gender Differences in the Meaning of Memorable Gifts. Psychology \& Marketing, 15, 81-109. https://doi.org/10.1002/(SICI)1520-6793(199801)15:1<81::AID-MAR6>3.0.CO;2-J

Baskin, E., Wakslak, C. J., Trope, Y., \& Novemsky, N. (2014). Why Feasibility Matters More to Gift Receivers than to Givers: A Construal-Level Approach to Gift Giving. Journal of Consumer Research, 41, 169-182. https://doi.org/10.1086/675737

Belk, R. W. (1991). The Ineluctable Mysteries of Possessions. Journal of Social Behavior \& Personality, 6, 17-55.

Belk, R. W., \& Coon, G. S. (1993). Gift Giving as a Gapic Love: An Alternative to the Exchange Paradigm Based on Dating Experiences. Journal of Consumer Research, 20, 393-417. https://doi.org/10.1086/209357

Bhattacharjee, A., \& Mogilner, C. (2014). Happiness from Ordinary and Extraordinary Experiences. Journal of Consumer Research, 41, 1-17.

https://doi.org/10.1086/674724

Bond, R., \& Smith, P. B. (1996). Culture and Conformity: A Meta-Analysis of Studies Using Asch's (1952b, 1956) Line Judgment Task. Psychological Bulletin, 119, 111-137. https://doi.org/10.1037/0033-2909.119.1.111

Bradford, T. W., \& Sherry Jr., J. F. (2013). Orchestrating Rituals through Retailers: An Examination of Gift Registry. Journal of Retailing, 89, 158-175.

https://doi.org/10.1016/j.jretai.2013.01.005

Caplow, T. (1982). Christmas Gifts and Kin Networks. American Sociological Review, 47, 383-392. https://doi.org/10.2307/2094994

Carter, T. J., \& Gilovich, T. (2010). The Relative Relativity of Material and Experiential Purchases. Journal of Personality and Social Psychology, 98, 146-159.

https://doi.org/10.1037/a0017145

Cavanaugh, L. A., Gino, F., \& Fitzsimons, G. J. (2015). When Doing Good Is Bad in Gift Giving: Mis-Predicting Appreciation of Socially Responsible Gifts. Organizational Behavior \& Human Decision Processes, 131, 178-189. 
https://doi.org/10.1016/j.obhdp.2015.07.002

Chan, C., Van Boven, L., Andrade, E. B., \& Ariely, D. (2014). Moral Violations Reduce Oral Consumption. Journal of Consumer Psychology, 24, 381-386. https://doi.org/10.1016/j.jcps.2013.12.003

Dibble, J. L., Levine, T. R., \& Park, H. S. (2012). The Unidimensional Relationship Closeness Scale (URCS): Reliability and Validity Evidence for a New Measure of Relationship Closeness. Psychological Assessment, 24, 565-572. https://doi.org/10.1037/a0026265

Dunn, E. W., Aknin, L. B., \& Norton, M. I. (2014). Prosocial Spending and Happiness: Using Money to Benefit Others Pays off. Current Directions in Psychological Science, 23, 41-47. https://doi.org/10.1177/0963721413512503

Epley, N., Keysar, B., Gilovich, T., \& Van Boven, L. (2004). Perspective Taking as Egocentric Anchoring and Adjustment. Social Science Electronic Publishing, 87, 327.

Epley, N., Morewedge, C. K., \& Keysar, B. (2004). Perspective Taking in Children and Adults: Equivalent Egocentrism but Differential Correction. Journal of Experimental Social Psychology, 40, 768. https://doi.org/10.1016/j.jesp.2004.02.002

Epley, N., Savitsky, K., \& Gilovich, T. (2002). Empathy Neglect: Reconciling the Spotlight Effect and the Correspondence Bias. Journal of Personality and Social Psychology, 83, 300-312. https://doi.org/10.1037/0022-3514.83.2.300

Flynn, F. J., \& Lake, V. K. B. (2008). If You Need Help, Just Ask: Underestimating Compliance with Direct Requests for Help. Journal of Personality and Social Psychology, 95, 128-143. https://doi.org/10.1037/0022-3514.95.1.128

Fujita, K., Trope, Y., Liberman, N., \& Levin-Sagi, M. (2006). Construal Levels and Self-Control. Journal of Personality and Social Psychology, 90, 351-367. https://doi.org/10.1037/0022-3514.90.3.351

Giesler, M. (2006). Consumer Gift Systems. Journal of Consumer Research, 33, 283-290. https://doi.org/10.1086/506309

Gilovich, T., Kumar, A., \& Jampol, L. (2015). A Wonderful Life: Experiential Consumption and the Pursuit of Happiness. Journal of Consumer Psychology, 25, 152-165. https://doi.org/10.1016/j.jcps.2014.08.004

Gilovich, T., Medvec, V. H., \& Savitsky, K. (2000). The Spotlight Effect in Social Judgment: An Egocentric Bias in Estimates of the Salience of One's Own Actions and Appearance. Journal of Personality and Social Psychology, 78, 211-222. https://doi.org/10.1037/0022-3514.78.2.211

Gilovich, T., Savitsky, K., \& Medvec, V. H. (1998). The Illusion of Transparency: Biased Assessments of Others' Ability to Read One's Emotional States. Journal of Personality and Social Psychology, 75, 332-346. https://doi.org/10.1037/0022-3514.75.2.332

Gino, F., \& Flynn, F. J. (2011). Give Them What They Want: The Benefits of Explicitness in Gift Exchange. Journal of Experimental Social Psychology, 47, 922. https://doi.org/10.1016/j.jesp.2011.03.015

Givi, J., \& Galak, J. (2017). Sentimental Value and Gift Giving: Givers Fears of Getting It Wrong Prevents Them from Getting It Right. Journal of Consumer Psychology, 27, 473-479. https://doi.org/10.1016/j.jcps.2017.06.002

Gouldner, A. W. (1960). The Norm of Reciprocity: A Preliminary Statement. American Sociological Review, 25, 161-178. https://doi.org/10.2307/2092623

Hutcherson, C. A., Seppala, E. M., \& Gross, J. J. (2008). Loving-Kindness Meditation Increases Social Connectedness. Emotion, 8, 720-724. https://doi.org/10.1037/a0013237

Joy, A. (2001). Gift Giving in Hongkong and the Continuum of Social Ties. Journal of 
Consumer Research, 28, 239-256. https://doi.org/10.1086/322900

Keinan, A., \& Kivetz, R. (2006). Repenting Hyperopia: An Analysis of Self-Control Regrets. Journal of Consumer Research, 33, 273-282.

Kenny, D. A., \& Acitelli, L. K. (2001). Accuracy and Bias in the Perception of the Partner in a Close Relationship. Journal of Personality and Social Psychology, 80, 439-448. https://doi.org/10.1037/0022-3514.80.3.439

Klein, J. G., Lowrey, T. M., \& Otnes, C. C. (2015). Identity-Based Motivations and Anticipated Reckoning: Contributions to Gift-Giving Theory from an Identity-Stripping Context. Journal of Consumer Psychology, 25, 431-448.

https://doi.org/10.1016/j.jcps.2015.01.003

Kok, B. E., \& Fredrickson, B. L. (2010). Upward Spirals of the Heart: Autonomic Flexibility, as Indexed by Vagal Tone, Reciprocally and Prospectively Predicts Positive Emotions and Social Connectedness. Biological Psychology, 85, 432-436. https://doi.org/10.1016/j.biopsycho.2010.09.005

Kok, B. E., Coffey, K. A., Cohn, M. A., Catalino, L. I., Vacharkulksemsuk, T., Algoe, S. B. et al. (2013). Running Head: Positive Emotions, Social Connections, and Health 1 How Positive Emotions Build Physical Health: Perceived Positive Social Connections Account for the Upward Spiral between Positive Emotions and Vagal Tone. Psychological Science, 24, 1123-1132. https://doi.org/10.1177/0956797612470827

Larsen, D., \& Watson, J. J. (2010). A Guide Map to the Terrain of Gift Value. Psychology \& Marketing, 18, 889-906. https://doi.org/10.1002/mar.1034

Lerouge, D., \& Warlop, L. (2006). Why It Is So Hard to Predict Our Partner's Product Preferences: The Effect of Target Familiarity on Prediction Accuracy. Journal of Consumer Research, 33, 393-402. https://doi.org/10.1086/508523

Lu, J. Y., Xie, X. F., \& Xu, J. Z. (2013). Desirability or Feasibility: Self-Other Decision-Making Differences. Personality and Social Psychology Bulletin, 39, 144-155. https://doi.org/10.1177/0146167212470146

Luo, S., \& Snider, A. G. (2010). Accuracy and Biases in Newlyweds' Perceptions of Each Other: Not Mutually Exclusive But Mutually Beneficial. Psychological Science, 20, 1332-1339. https://doi.org/10.1111/j.1467-9280.2009.02449.x

Mogilner, C., Kamvar, S. D., \& Aaker, J. (2010). The Shifting Meaning of Happiness. Research Papers, 2, 395-402.

Neff, L. A., \& Karney, B. R. (2005). To Know You Is to Love You: The Implications of Global Adoration and Specific Accuracy for Marital Relationships. Journal of Personality and Social Psychology, 88, 480-497. https://doi.org/10.1037/0022-3514.88.3.480

Nickerson, R. S. (1999). How We Know-And Sometimes Misjudge-What Others Know: Imputing One's Own Knowledge to Others. Psychological Bulletin, 125, 737-759. https://doi.org/10.1037/0033-2909.125.6.737

Paolacci, G., Straeter, L. M., \& De Hooge, I. E. (2015). Give Me Your Self: Gifts Are Liked More When They Match the Giver's Characteristics. Journal of Consumer Psychology, 25, 487-494. https://doi.org/10.1016/j.jcps.2015.01.006

Pickett, C. L., Gardner, W. L., \& Knowles, M. (2004). Getting a Cue: The Need to Belong and Enhanced Sensitivity to Social Cues. Personality and Social Psychology Bulletin, 30, 1095-1107. https://doi.org/10.1177/0146167203262085

Rosenzweig, E., \& Gilovich, T. (2012). Buyer's Remorse or Missed Opportunity? Differential Regrets for Material and Experiential Purchases. Journal of Personality and Social Psychology, 102, 215-223. https://doi.org/10.1037/a0024999

Ross, L., Greene, D., \& House, P. (1977). The "False Consensus Effect": An Egocentric 
Bias in Social Perception and Attribution Processes. Journal of Experimental Social Psychology, 13, 279-301. https://doi.org/10.1016/0022-1031(77)90049-X

Roster, C. A. (2010). Moments of Truth in Gift Exchanges: A Critical Incident Analysis of Communication Indicators Used to Detect Gift Failure. Psychology \& Marketing, 23, 885-903. https://doi.org/10.1002/mar.20138

Rugimbana, R., Donahay, B., Neal, C., \& Polonsky, M. J. (2003). The Role of Social Power Relations in Gift Giving on Valentine's Day. Journal of Consumer Behaviour, 3, 63-73. https://doi.org/10.1002/cb.122

Ruth, J., Otnes, C., \& Brunel, F. (1999). Gift Receipt and the Reformulation of Interpersonal Relationships. Journal of Consumer Research, 25, 385-402. https://doi.org/10.1086/209546

Savitsky, K., Epley, N., \& Gilovich, T. (2001). Do Others Judge Us as Harshly as We Think? Overestimating the Impact of Our Failures, Shortcomings, and Mishaps. Journal of Personality and Social Psychology, 81, 44-56. https://doi.org/10.1037/0022-3514.81.1.44

Schiffman, L. G., \& Cohn, D. Y. (2009). Are They Playing by the Same Rules? A Consumer Gifting Classification of Marital Dyads. Journal of Business Research, 62, 1054-1062. https://doi.org/10.1016/j.jbusres.2008.09.012

Segev, R., Shoham, A., \& Ruvio, A. (2012). What Does This Gift Say about Me, You, and Us? The Role of Adolescents' Gift Giving in Managing Their Impressions among Their Peers. Psychology \& Marketing, 29, 752-764. https://doi.org/10.1002/mar.20561

Shen, H., Wan, F., \& Wyer, R. S. (2011). Cross-Cultural Differences in the Refusal to Accept a Small Gift: The Differential Influence of Reciprocity Norms on Asians and North Americans. Journal of Personality and Social Psychology, 100, 271-281. https://doi.org/10.1037/a0021201

Sherry Jr., J. F. (1983). Gift Giving in Anthropological Perspective. Journal of Consumer Research, 10, 157. https://doi.org/10.1086/208956

Steffel, M., \& Leboeuf, R. A. (2014). Over-Individuation in Gift Giving: Shopping for Multiple Recipients Leads Givers to Choose Unique But Less Preferred Gifts. Social Science Electronic Publishing, 40, 1167-1180.

Tamir, D. I., \& Mitchell, J. P. (2012). Disclosing Information about the Self Is Intrinsically Rewarding. Proceedings of the National Academy of Sciences, 109, 8038-8043. https://doi.org/10.1073/pnas.1202129109

Teigen, K. H., Olsen, M. V. G., \& Solås, O. E. (2011). Giver-Receiver Asymmetries in Gift Preferences. British Journal of Social Psychology, 44, 125-144. https://doi.org/10.1348/014466604X23428

Unity Marketing (2015). Gifting Report 2015: The Ultimate Guide to the Consumer Gift-Giving Market.

Van Boven, L., Dunning, D., \& Loewenstein, G. (2000). Egocentric Empathy Gaps between Owners and Buyers: Misperceptions of the Endowment Effect. Journal of Personality and Social Psychology, 79, 66-76. https://doi.org/10.1037/0022-3514.79.1.66

Ward, M. K., \& Broniarczyk, S. M. (2011). It's Not Me, It's You: How Gift Giving Creates Giver Identity Threat as a Function of Social Closeness. Journal of Consumer Research, 38, 164-181. https://doi.org/10.1086/658166

Ward, M. K., \& Broniarczyk, S. M. (2016). Ask and You Shall (Not) Receive: Close Friends Prioritize Relational Signaling over Recipient Preferences in Their Gift Choices. Journal of Marketing Research, 53, 1001-1018. https://doi.org/10.1509/jmr.13.0537

Xu, J.-Z., \& Xie, X.-F. (2011). Self-Other Decision Making Difference: A Construal Level 
Perspective. Acta Psychologica Sinica, 43, 11-20.

https://doi.org/10.3724/SP.J.1041.2011.00011

Yang, A. X., \& Urminsky, O. (2015). The Foresight Effect: Local Optimism Motivates Consistency and Local Pessimism Motivates Variety. Journal of Consumer Research, 42, 361-377. https://doi.org/10.1093/jcr/ucv039

Yang, Y., \& Galak, J. (2015). Sentimental Value and Its Influence on Hedonic Adaptation. Journal of Personality and Social Psychology, 109, 767-790. https://doi.org/10.1037/pspa0000036

Zhang, Y., \& Epley, N. (2012). Exaggerated, Mispredicted, and Misplaced: When "It's the Thought That Counts" in Gift Exchanges. Journal of Experimental Psychology General, 141, 667-681. https://doi.org/10.1037/a0029223 